\title{
Mastitis canina gangrenosa: reporte de caso
}

\author{
Gangrenous canine mastitis: case report
}

\author{
Pavan Leticia ${ }^{1}$ MV; Estrada RV Cristhian ${ }^{1}$ MVZ; Silva DP Priscilla ${ }^{1}$ MV; Mucédola Talita ${ }^{1}$ MV; \\ Uscategui Ricardo²* Ph.D; Apparicio Maricy ${ }^{1}$ Ph.D; Toniolo H Gilson ${ }^{1}$ Ph.D; Vicente RR Wilter ${ }^{1}$ Ph.D.
}

¿Universidad Estadual Paulista "Júlio de Mesquita Filho" (Unesp), Faculdade de Ciencias Agrárias y Veterinárias (FCAV), Departamento de Medicina Veterinária Preventiva y Reproducción Animal, Jaboticabal, SP, Brasil.

2Universidade Estadual Paulista "Júlio de Mesquita Filho" (Unesp), Faculdade de Ciencias Agrárias e Veterinárias (FCAV), Departamento de Clínica y Cirurgia veterinária, Jaboticabal, SP, Brasil.

\section{Keywords:}

Antibiogram; Staphylococcus; contaminated wound; sugar; magnesium hydroxide.

\begin{abstract}
Mastitis is an infectious and inflammatory process of the mammary gland, which alters glandular tissues, and the physical, chemical and bacteriological milk aspects. Canine mastitis occurs more frequently during the postpartum period or after repeated episodes of seudogestation and is related to excessive milk production and accumulation. The present report, aims to related, describe and discuss the occurrence, diagnosis, treatment and evolution of a acute gangrenous mastitis case in an adult bitch during the postpartum period, the importance of a correct diagnosis, selection of antimicrobial therapy based In the antibiogram tests and the topical alterative treatment with sugar and magnesium hydroxide association. Conclusion, gangrenous mastitis is a serious disease in the small animal clinic, the success of its treatment depends on the adequate selection of antimicrobial treatment based on culture and antibiogram exams, as well as an adequate support treatment of lesions and secondary clinical complications.
\end{abstract}

\section{Palabras Clave:}

Antibiograma;

Staphylococcus; herida contaminada; azúcar; hidróxido de magnesio.

INFORMACIÓN

Recibido: 19-02-2017;

Aceptado: $12-06-2017$. Correspondencia autor: ramirezuscategui@hotmail.com

\section{Resumen}

Mastitis es un proceso infeccioso e inflamatorio de la glándula mamaria, que altera el tejido glandular, y los aspectos físicos, químicos y bacteriológicos de la leche. La mastitis en caninos se presenta con mayor frecuencia durante el periodo postparto o después de repetidos episodios de gestación sicológica e está relacionada con la excesiva producción y acumulación de leche. El presente reporte tiene como objetivo relatar, describir y discutir la ocurrencia, diagnóstico, tratamiento y evolución de un caso de mastitis gangrenosa aguda en una hembra canina adulta durante el periodo postparto, la importancia de un diagnóstico certero, la selección de la terapia antimicrobiana basada en los test de antibiograma y el tratamiento tópico alterativo, asociando azúcar e hidróxido de magnesio al mismo. Como conclusión la mastitis gangrenosa es una enfermedad grave en la clínica de pequeños animales, el éxito de su tratamiento depende de la selección adecuada del tratamiento antimicrobiano basado en el cultivo y antibiograma, así como de un tratamiento de soporte adecuado de las lesiones y complicaciones clínicas secundarias. 


\section{Introducción}

Se define como mastitis al proceso infeccioso e inflamatorio de la glándulas mamaria, que genera alteraciones en el tejido glandular y modifica los aspectos físicos, químicos y bacteriológicos de la leche. Esta enfermedad puede ocurrir por múltiples factores como alergias, alteraciones metabólicas, traumas e infecciones por hongos, levaduras y con mayor frecuencia por bacterias (ALVES, 2008; NASCIMENTO et al., 2016).

La mastitis en hembras caninas es común en el periodo postparto o durante episodios repetidos de gestación sicológica, estando relacionada con la excesiva producción y retención de leche, por camadas de tamaño reducido, muerte de neonatos, tratamiento inconsistente de la seudolactancia e inclusive falta de higiene de la glándula mamaria (VERVERIDIS et al., 2007). Los agentes bacterianos aislados con más frecuencia en esta patología son Escherichia coli, Streptococcus spp e Staphylococcus spp (S. aureus, S. pseudintermedius, coagulase-negative Staphylococci) (ORFANOU et al., 2016). Y en casos de tratamiento inexistente, inadecuado o tardío, esta enfermedad puede evolucionar para mastitis gangrenosa o sepsis, pudiendo agravar el estado clínico general e incluso provocando la muerte del animal (OLIVEIRA et al., 2015).

Los signos clínicos clásicos de esta enfermedad incluyen: enrojecimiento e inflamación de la glándula mamaria, inapetencia, consistencia dura de las glándulas mamarias y en casos avanzados fiebre, dolor a la palpación de las glándulas afectadas, secreción purulenta, hemorragia y fistulas (BABA, 2016). Las características histopatológicas en fases agudas son infiltración neutrofílica, hemorragia, destrucción de células epiteliales mamarias y alveolares, ya en fases avanzadas, perdida de la arquitectura glandular, infiltración linfocítica y fibrosis del tejido glandular. El diagnóstico precoz de la mastitis es de gran importancia para el pronóstico y tratamiento del paciente, que inicialmente se puede realizar con base a los hallazgos clínicos, en cuanto se realiza la confirmación y clasificación etiológica mediante el análisis bacteriológico de las secreción mamaria por, citología, examen de "white side", tinción de Giemsa y cultivo (ORFANOU et al., 2016) y se define el tratamiento antimicrobiano adecuado con base en los tipos de bacterias presentes y el estudio de antibiograma.

El presente reporte de caso tiene como objetivo relatar, describir y discutir la ocurrencia, diagnóstico, tratamiento y evolución de mastitis gangrenosa aguda postparto en una hembra canina adulta.

\section{Descripción de caso}

La paciente era una hembra canina, de raza fila brasilero, con seis años de edad, peso corporal de 33 kilogramos y entera que fue llevada por sus tutores para consulta en el sector de Obstetricia y Reproducción Animal del Hospital Veterinario "Governador Laudo Natel" de la FCAV-Unesp, campus de Jaboticabal, Brasil.

El motivo principal de consulta descrito por los tutores era: aumento de volumen en las glándulas mamarias torácicas del lado derecho. En la anamnesis se identificó que aproximadamente tres meses atrás esta paciente había parido seis crías, siendo este su primer parto, dos de los neonatos murieron y la madre amamanto las cuatro crías restantes durante dos meses. Además de la inflamación de la glándula mamaria, fue descrita apatía y anorexia de dos días de evolución.

Al examen clínico fue identificada inflamación (edema, rubor, tumefacción, dolor y aumento de la temperatura) de las mamas torácicas (M1 y M2). La glándula clínicamente más afectada era la M2 que media aproximadamente $15 \times 12 \times 12 \mathrm{~cm}$, presentaba consistencia dura a la palpación y una región donde era posible observar una porción de piel más delgada (Figura 1A). La paciente presentaba taquipnea (30 respiraciones/minuto), taquicardia (128 latidos/minuto), hipertermia $\left(39,6^{\circ} \mathrm{C}\right)$, mucosas oral y ocular pálidas y una baja condición corporal (4/9). Con diagnóstico presuntivo de mastitis, objetivando realizar el diagnóstico etiológico, definir el tratamiento más apropiado y tratando de descartar otras alteraciones (neoplasia mamaria y sepsis principalmente), fueron solicitados como exámenes complementares: cultivo bacteriológico y antibiograma de la secreción mamaria, hemograma, concentración sérica de creatinina y alanino aminotransferasa (ALT) y ecografía da glándula mamaria. Encontrando las siguientes alteraciones: leucocitosis (34800 Leuc/ $\mu \mathrm{L}$ ) principalmente neutrofílica (33.756 Neut/ $\mu \mathrm{L}$ ) y con presencia de granulaciones toxicas (Tabla 1); y a la ecografía se describe un tejido mamario inflamado, una región aparentemente quística con contenido anecóico y presencia de bastantes detritos celulares. No obstante el resultado de los análisis microbiológicos demoran hasta $72 \mathrm{~h}$ en ser reportados.

Con base al cuadro clínico y resultados parciales de los exámenes complementarios, se inició tratamiento oral con dipirona (25 mg/kg cada $12 \mathrm{~h}$ ), cefalexina (30 mg/kg cada $12 \mathrm{~h}$ ), omeprazol (1 mg/kg cada $24 \mathrm{~h}$ ), meloxicam $(0,1 \mathrm{mg} / \mathrm{kg}$ cada $24 \mathrm{~h}$ ) limpieza con iodo povidona (cada $12 \mathrm{~h}$ ) de las glándulas afectadas y compresas calientes y frías (cada 12h), objetivando controlar la inflamación, el dolor e iniciar la antibioterapia de amplio espectro para el control de la mastitis clínica. 


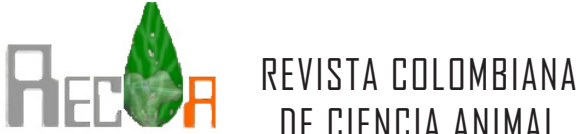

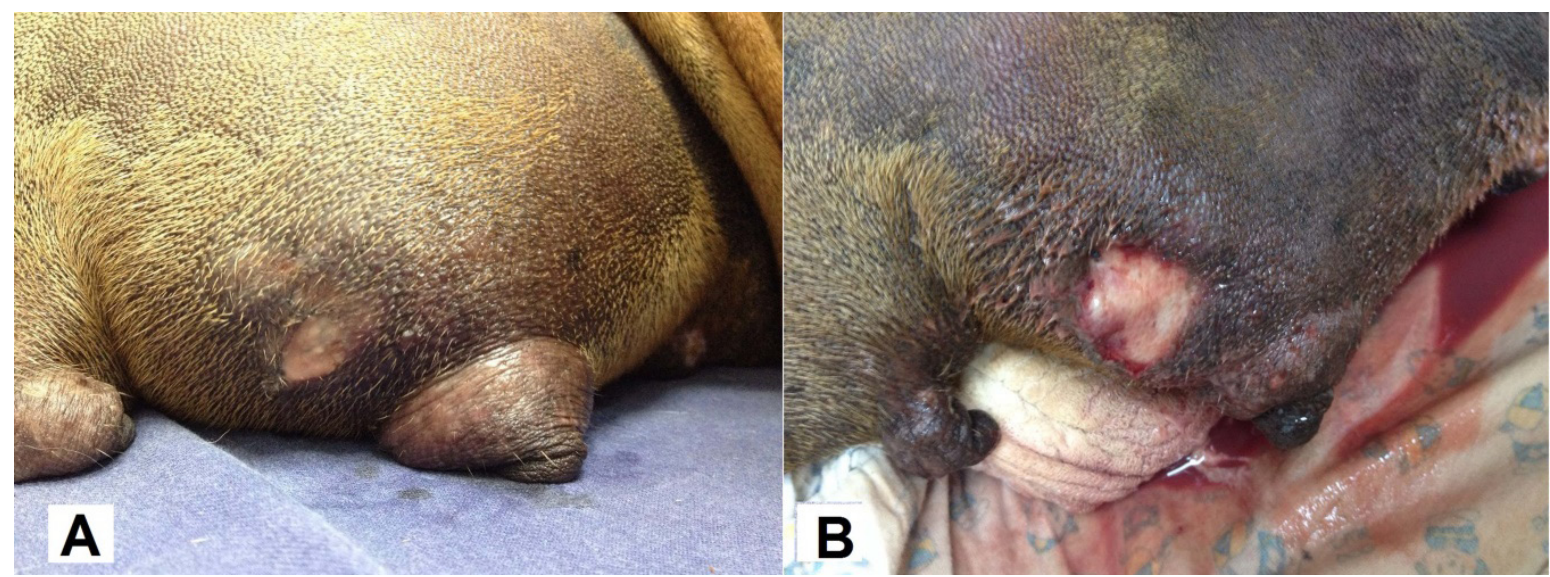

Figura 1. Imagen fotográfica de mastitis gangrenosa en hembra canina adulta. A) Inflamación del tejido glandular derecho de consistencia dura. B) Ulceración del tejido glandular e drenaje de secreción serosanguinolenta.

Tabla 1. Parámetros hematológicos y bioquímicos en una hembra canina adulta afectada por mastitis gangrenosa postparto, en la consulta inicial y después de 7 y 30 días de instaurado el tratamiento.

\begin{tabular}{cccc}
\hline Parámetro & Consulta inicial & $\mathbf{7}^{\circ}$ Día & $\mathbf{3 0}^{\circ}$ Día \\
\hline Eritrocitos $/ \mu \mathrm{L}$ & 5.890 .000 & 5.060 .000 & 5.310 .000 \\
Hematócrito $\%$ & 38,30 & 33,60 & 35,90 \\
Hemoglobina g/dL & 13,70 & 11,30 & 12,20 \\
VCM fL & 65,02 & 66,40 & 67,60 \\
HCM pg & 23,25 & 22,33 & 22,97 \\
CHCM g/dL & 35,77 & 33,63 & 33,98 \\
Plaquetas $/ \mu \mathrm{L}$ & 200.000 & 439.000 & 190.000 \\
Leucocitos $/ \mu \mathrm{L}$ & 34.800 & 10.900 & 8.100 \\
Neutrófilos $/ \mu \mathrm{L}$ & 33.756 & 8.066 & 5.832 \\
Linfocitos $/ \mu \mathrm{L}$ & 696 & 1.090 & 1.296 \\
Monocitos $/ \mu \mathrm{L}$ & 348 & 436 & 162 \\
Eosinófilos $/ \mu \mathrm{L}$ & 0 & 1.308 & 810 \\
Bandas $/ \mu \mathrm{L}$ & 0 & 0 & 0 \\
Creatinina $\mathrm{mg} / \mathrm{dL}$ & 1,00 & -- & 1,30 \\
ALT $\mathrm{U} / \mathrm{L}$ & 20,00 & -- & 36,00 \\
\hline
\end{tabular}

Al día siguiente, la paciente retorno al hospital por complicación del cuadro clínico. Los propietarios reportaron que habían realizado el tratamiento recomendado, pero su animal continuaba apático, anoréxico y parecía febril. Al examen clínico se detectó que el tejido mamario se encontraba más blando en relación al día anterior la temperatura corporal estaba más alta $\left(40,4^{\circ} \mathrm{C}\right)$ y el estado clínico general de la paciente se había deteriorado. Debido a la evolución insatisfactoria la paciente fue internada e iniciada antibioterapia endovenosa de amplio espectro con la asociación de metronidazol (30 mg/kg cada $24 \mathrm{~h}$ ), y cefazolina ( $30 \mathrm{mg} / \mathrm{kg}$ cada $12 \mathrm{~h}$ ), además fue instituido clorhidrato de tramadol (4 mg/kg cada $8 \mathrm{~h}$ ) por vía intramuscular para controlar el dolor, fluidoterapia de soporte (Ringer con lactato $60 \mathrm{ml} / \mathrm{kg} / \mathrm{día}$ ) y se continuo la terapia local propuesta.
Cuarenta y ocho horas (día 2) de la evaluación inicial, ocurrió ulceración del tejido mamario afectado y drenaje de gran volumen de secreción sero-sanguinolenta (Figura 1B). Por tal motivo, fue colocada una sonda uretral en la región ulcerada, para facilitar el drenaje y el tratamiento local consistente en lavado conspicuo con solución salina $(0,9 \%)$ e aplicación de hidróxido de magnesio $1200 \mathrm{mg}$ (cada 12h), este último con el objetivo de alcalinizar el medio, visto que las bacterias generalmente aisladas en la mastitis canina se multiplican en medio acido (Figura 2A).

Apenas 48 horas después de la ulceración (día 4) se obtuvo el resultado del cultivo de la secreción mamaria, siendo aislado Staphylococcus sp coagulase positivo. $\mathrm{Y}$ al antibiograma el agente resulto resistente a los fármacos antimicrobianos que estaban siendo administrando, por lo cual, estos fueron modificados en base a la sensibilidad y buena respuesta teórica por la asociación oral (debido a la inexistencia de solución inyectable) de amoxicilina con ácido clavulánico (22 mg/ kg cada 12h) a partir de ese día.

Al séptimo día de la consulta inicial, se observó reducción en el volumen de secreción mamaria, en este momento y con el fin de favorecer ya el proceso cicatrizar, el hidróxido de magnesio fue substituido por una pomada que asociaba Nitrofural $0,002 \%$ (Furacin®) y azúcar blanca.

Durante el periodo de hospitalización, la paciente presento evolución progresiva y satisfactoria del cuadro clínico a partir del día de ulceración, disminuyendo la inflamación, el dolor, la apatía y la anorexia. Pasados siete días a partir de la consulta inicial fue repetido el cuadro hemático, corroborando la resolución de la leucocitosis (10.900 Leu/ $\mu \mathrm{L})$ (Tabla 1$)$. En el $11^{\circ}$ día (Figura 2B) se dio de alta a la paciente manteniendo 


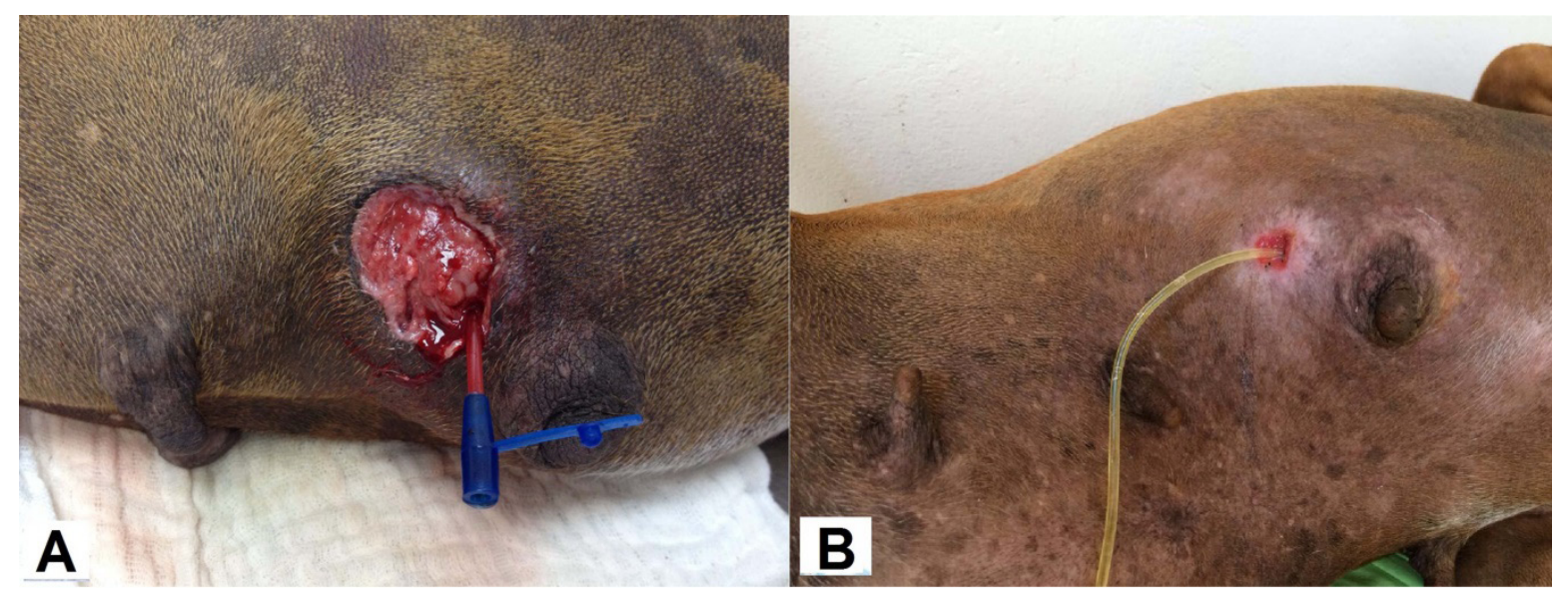

Figura 2. Imagen fotográfica del proceso evolutivo en una hembra canina adulta afectada por mastitis gangrenosa postparto. A) Limpieza del tejido glandular por medio de una sonda uretral ( $4^{\circ}$ día). B) posterior a 15 días de tratamiento.

el tratamiento antibiótico y las limpiezas con solución fisiológica por 10 días más, y se recomendó realizar ovario histerectomía.

Pasados 30 días de la primera consulta, la paciente retorno para su control final, fueron repetidos los exámenes de laboratorio iniciales para control y como evaluación pre-operatoria, sin embargo este examen reportó trombocitopenia (190000 Plaq/ $\mu \mathrm{L}$, tabla 1) y por el histórico, presencia de abundantes ectoparásitos y epidemiologia de la región de solicito prueba de lgG de Erlichia canis (ImmunoComb®) resultando positivo. En este momento, se indicó el tratamiento padrón para hemoparásitos y ectoparásitos antes de realizar el procedimiento quirúrgico, sin embargo, los propietarios no retornaron nuevamente.

\section{Discusión}

El Staphylococcus coagulase-positivo, aislado en el presente relato, pertenece al grupo de los principales agentes causadores de mastitis en hembras caninas, que generalmente ocurre posterior a la muerte o el desteto de una camada, durante la involución de la glándula mamaria. La principal puerta de acceso de este microrganismo, es por el ducto de la glándula y puede afectar una o más de estas glándulas (ORFANOU et al., 2016).

El diagnóstico es realizado básicamente por la sintomatología clínica, consistente en: edema, hiperemia, dolor, pérdida del apetito e incapacidad para amamantar las crías, pudiendo evolucionar al abandono y a la mastitis gangrenosa (BOROWSKY et al., 2003). Además de los signos clínicos comunes, esta paciente presento necrosis y ulceración rápida del tejido mamario, sin embargo este tipo de complicación es mas de carácter crónico (NASCIMENTO et al., 2016).
La ecografía utilizada como recurso diagnóstico complementario, auxilio en la identificación de la inflamación, descarte de otro tipo de lesiones como lo son las neoplasias y además indico la colección de un exudado al interior de la propia glándula. Estos hallazgos son compatibles con la literatura que describe el tejido inflamado con ecogenicidad disminuida y dificultad para distinguir los tejidos adyacentes, cuando se compara con una glándula mamaria sana (TRASCH et al., 2007).

Es importante destacar aquí que, antes de comenzar con un tratamiento antimicrobiano en estos casos, se deben tener en cuenta los efectos secundarios de estos fármacos, tanto en la hembra como en sus crías si la misma se encuentra amamantando. Un estudio epidemiológico demostró que: gentamicina, enrrofloxacina, nitrofurantoina y amoxicilina con ácido clavulánico son generalmente eficaces para el tratamiento de mastitis por Staphylococcus de acuerdo con los test de sensibilidad (JUNG et al., 2002). En este sentido, la selección del tratamiento antibiótico inicial basado en el cuadro y experiencia clínica, no fue efectiva, ya que el microrganismo aislado no resultó sensible a ninguna de las cefalosporinas ni nitroimizoles utilizados. Por tal motivo, es importante dar énfasis a la indicación y uso de los exámenes microbiológicos, principalmente el antibiograma, no solo por la eficacia en el tratamiento que estos exámenes aportan, sino también por el uso consiente y racional de los antibióticos, influenciando directamente en los factores de resistencia microbiana, así como en los efectos adversos que muchos de estos principios pueden ejercer en los pacientes (JUNG et al., 2002). De esta manera, la selección de amoxicilina con ácido clavulánico basada en la sensibilidad del microrganismo propició una evolución rápida y satisfactoria del cuadro clínico y celular, que no hubiera sido posible sin la utilización de estas herramientas paraclínicas. 
Además del tratamiento sistémico, la terapia local fue un coadyuvante de gran relevancia es este caso. La limpieza con solución fisiológica y la aplicación de nuitrofuranos tópicos son estrategias ya consagradas, sin embargo, el uso de hidróxido de magnesio, y azúcar hacen parte de terapias poco conocidas, utilizadas y limitadamente descritas en la literatura, pero que resultan en un control eficiente de la infección y auxilian el proceso cicatricial. En este sentido, la acción del azúcar granulado se basa en su alta osmolaridad, que genera alteración sobre el medio de crecimiento y desenvolvimiento de las bacterias, principalmente de la E. coli, Streptococcus y Staphylococcus, ayuda a favorecer el desarrollo de tejido de granulación y retira el tejido necrótico (MATHEWS y BINNINGTON, 2002).

El azúcar lejos de ser una alternativa terapéutica ampliamente utilizada, ya ha sido bastante estudiada y sus beneficios relatados. Pero este no es el caso del hidróxido de magnesio (conocido popularmente como leche de magnesia Phillips), sustancia utilizada como antiácido y laxante, que en la década de los 90's demostró una efectiva acción antimicrobiana invitro (Staphylococcus aureus, E. coli, Pseudomonas, Klebsiella y Streptococcus), aplicable al tratamiento de heridas contaminadas (ROCHA et al., 1990). Sin embargo, pese a estas propiedades, apenas fueron encontrados estudios experimentales evaluando el efecto de esta sustancia en heridas inducidas en ratones (SPASOV et al., 2001; ALIZADEH et al., 2007). Estos estudios relatan potentes efectos antimicrobianos y cicatriciales, atribuidos a la estimulación de la fagocitosis, alteración del $\mathrm{pH}$ de la herida, efecto bactericida directo y estimulación de la producción de colágeno. Con base en estos preceptos, es posible atribuir los efectos benéficos obtenidos con el uso esta substancia a sus propiedades, en una herida fuertemente contaminada por Staphylococcus coagulase-positivos.

El pronóstico de hembras caninas con mastitis generalmente es favorable (BOROWSKY et al., 2003), si se realiza un diagnóstico rápido y se instaura iun tratamiento adecuado. En este sentido, el examen de sensibilidad y la terapia local se consideran factores primordiales para la cura de esta lesión y la mejora clínica progresiva del paciente.

\section{Conclusión}

Como conclusión la mastitis gangrenosa es una enfermedad grave en la clínica de pequeños animales, el éxito de su tratamiento depende de la selección adecuada del tratamiento antimicrobiano basado en el cultivo y antibiograma, así como de un tratamiento de soporte adecuado de las lesiones y complicaciones clínicas secundarias.

\section{Referencias}

ALIZADEH, A.; MOHAGHEGHI, M.; KHANEKI, M.; SAEED, PK. 2007. A study of the effect of magnesium hydroxide on the wound healing process in rats. Medical Journal of Islamic World Academy of Sciences 16:165-70.

ALVES, R. M; SANTOS, M. W; INFORZATO, R. G. 2008. Mastite - diagnóstico, tratamento e prevenção: Revisão de literatura. Revista científica eletrônica de medicina veterinária 6(10): 1-6.

BABA, A. E. 2016. Mastitis en canino, un caso clínico. REDVET - Revista electrónica de Veterinaria 17 (4): 1-3

BOROWSKY, L. M.; DRIEMEIER, D.; ROZZA, D. B.; CARDOSO, M. R. I. 2003. Mastite com septicemia em caninos causada por Sthaphylococcus intermedius. Acta Scientiae Veterinariae 31 (2): 111-113.

JUNG, C.; WEHREND, A.; BOSTED, H. 2002. Investigation about the incidence, differention and microbiology of canine mastitis. Prakitsche Tieraszt 83: 508-511.

MATHEWS, K. A.; BINNINGTON, A. G. 2002. Wound management using sugar. Compendium on Continuing Education for the Practising Veterinarian 24(1):41-50.

NASCIMENTO, M. A; VALERIANO, K; CAMPOS, G. A; SILVA, P; PRISCO, R. 2016. Mastite canina pós-parto: relato de caso. Em: Anais - VI Congresso de iniciação científica da fundação educacional de Ituverava. Disponível em: http://www.nucleus.feituverava.com.br/index.php/eventoscientificos/article/viewFile/2475/2191. Consultado en: mayo de 2017.

OLIVEIRA, N. S; ZAHN, S. F; DALANEZI, M. F; ARAUJO, B. E; SILVA C. L; PRESTES, N. 2015. Mastite necrosante em cadela: relato de caso. Veterinária e Zootecnia 22(3): 380-385. 
ORFANOU D.C; FTHENAKIS G.C; MAVROGIANNI V.S. 2016. Mastitis in lactating bitches. Proceedings of the 8th International Symposium on Canine and Feline Reproduction, ISCFR. Disponível em: http://www.ivis.org/proceedings/ iscfr/2016/169.pdf?LA=1. Consultado en: mayo de 2017.

ROCHA, J. J. R.; LEVY, C. E.; MAGALHÄES, M. A. S. R. 1990. Estudo in vitro da inibiçäo do crescimento de bactérias pelo hidróxido de magnésio. Acta Cirurgica Brasileira 5(4): 160-163.

SPASOV, A. A.; FOMICHEV, E. V.; GUSEVA, T. N.; MAZANOVA, L. S.; SHCHAVA, S. N. 2001. Efficiency of Magnesium-Containing Preparation Polykatan in Therapy of Purulent Wounds. Bulletin of Experimental Biology and Medicine 131(2): 132-135.

TRASCH, K.; WEHREND, A.; BOSTEDT, H. 2007. Ultrasonographic description of canine mastites. Veterinary Radiology \& Ultrasound 48(6): 580-584.

VERVERIDIS, H. N; MAVROGIANNI, V.S; FRAGKOU, I. A; ORFANOU, D. C; GOUGOULIS, D. A; TZIVARA, A; ATHANASIOU L; BOSCOS, C.M; FTHENAKIS, G.C. 2007. Experimental staphylococcal mastitis in bitches: Clinical, bacteriological, cytological, haematological and pathological features. Veterinary Microbiology 124(1-2): 95-106. 